\title{
Alguns aspectos da anatomia ecológica da folha de Prunus myrtifolia (L.) Urban - Rosaceae
}

\author{
Carlinda Pereira da Silva (') \\ Zélia Mạ Marquez da Rocha (') \\ Eduardo Lleras Pérez ( ${ }^{2}$ )
}

\begin{abstract}
Resumo
Foram estudadas variaçōes anatômicas de toınas de Prunus myrtifolia (L.) Urban, coletadas a diferentes alturas da copa, para observar se variações anatômicas ocorrem segundo padrōes já verificados para outras espécies. As folhas dos estratos superiores apresentaram, progressivamente, características mais xéricas que as dos estratos inferiores quanto à área foliar, estrutura e espessura do mesófilo, dimensão das células epidérmicas e número de estômatos por unidade de área. Postula-se que estas modificaçōes são induzidas por condições microclimáticas mais xéricas nos estratos mais altos.
\end{abstract}

\section{INTRODUÇÃo}

Este trabalho é mais uma contribuição ao conhecimento da anatomia ecológica de plantas amazônicas e, o que é mais importante, ao conhecimento das variações fenotípicas induzidas num mesmo genótipo por variações microclimáticas.

A variação anatômica em folhas de uma mesma espécie já está amplamente documentada na literatura (Esau, 1965; Salisbury, 1927 entre outros), assim como a influência de condições sobre eia; Boardman, 1977; Lleras, 1977 entre outros). Em condições naturais, enquanto as folhas superiores atingem níveis de saturação lumínica nas dos estratos inferiores o auto-sombreamento limita a incidência de luz que, segundo Medina (1972), se reflete na arquitetura de sua superfície assimilatória. L.leras ( $/ \mathrm{d}$ ) apresenta uma hipótese ecofisiológica que permite explicar as diversas modificações fenotípicas induzidas em um mesmo genótipo ao variar as condições microclimáticas.

Resultados de pesquisas anteriores (Salisbưry, 1977; Leite \& Lleras, 1978; Medri \& Lleras,
1979. 1980) sugerem um progressivo xeromorfismo foliar à média que se afasta dos estratos baixos para os apicais de uma mesma árvore.

\section{MATERIAL E MÉTODOS}

O material vegetal em estudo, Prunus myrtifolia (L.) Urban, foi coletado de uma árvore de mata secundária da área interna do Instituto Nacional de Pesquisas da Amazônia (INPA), situado no km 3 da Estrada do Aleixo, Manaus. Foram coletados ramos de três diferentes estratos da árvore: inferior $(2,5 \mathrm{~m}$ de altura), mediano $(8,0 \mathrm{~m}$ de altura) a superior $(16,0 \mathrm{~m}$ de altura), dos quais quinze folhas de cada estrato foram retiradas ao acaso para avaliação da área foliar e outras dez para estudos anatômicos. Os estudos anatômicos constaram de cortes transversais da região mediana da lâmina foliar. Para isso o material foi inicialmente fixado em Bouin, incluído em parafina e feito lâminas definitivas utilizando-se técnicas de dupla coloração (astrablau - fucsina básica). A epiderme, foi dissociada em água clorada, corada e montada para observações. As lâminas foram analisadas ao microscópio, os desenhos feitos em câmara clara e as áreas das células epidérmicas medidas com planímetro. A contagem dos estômatos foi feita em impressões epidérmicas retiradas do ápice, meio e base de cada uma das dez folhas. Avaliações estatísticas foram feitas utilizando-se o Teste de Mann-Whitney U (Siegel, 1956) .

\section{RESUltados E DISCUSSÃo}

ÁREA FOLIAR - Os valores obtidos para área foliar dos três estratos podem ser consultados na tabela I. Pode-se observar que a área foliar diminui com a altura da árvore.

(1) - Universidade Federal da Bahia, Salvador.

(2) - Instituto Nacional de Pesquisas da Amazônia, Manaus. 
Leite \& Lleras (1978), estudando a Euphorbiaceae Ponogophora schumburgkiana Miers, obtiveram rsultados significativos ao comparar as áreas foliares dos estratos inferiores $(1,6 \mathrm{r} \mathrm{m})$ em relação ao mediano $(2,80 \mathrm{~m}) \mathrm{e}$ superior $(4,60 \mathrm{~m})$, no entanto não tiveram resultados significativos quando compararam os estratos mediano e superior. Medri \& Lleras (1979) encontraram resultados altamente significativos quando da comparação dos estratos inferior $(6,0 \mathrm{~m})$ e mediano $(12,0 \mathrm{~m}) \mathrm{com}$ o superior $(13,0 \mathrm{~m})$ em uma Lecythidaceae, a Bertholietia excelsa Humb. \& Bonpl. Contudo, a comparação não foi significativa entre os estratos inferior e mediano. No presente estudo foi observada diferença significativa ( $P<$ 0,00001 ) ao comparar os estratos inferior $e$ mediano, mediano e superior e superior e inferior.

NÚMERO DE ESTÔMATOS - Salisbury (1927) e Meidner \& Mansfield (1968) observaram que o número de estômatos por unidade de área varia năo somente entre espécies, mas também dentro de uma espécie durante o crescimento e segundo a influência de fatores ambientais, anotando também que existe uma tendência de que folhas de inserção mais alta no caule

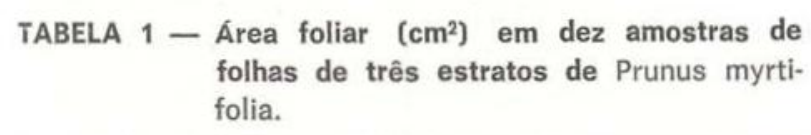
folhas de três estratos de Prunus myrtifolia.

\begin{tabular}{|c|c|c|c|}
\hline \multirow{2}{*}{ Amostras } & \multicolumn{3}{|c|}{ Estratos da árvore } \\
\hline & Inferior & Mediano & Superior \\
\hline 10 & 125,84 & 85,77 & 74,29 \\
\hline 9 & 133,03 & 91,82 & 79,63 \\
\hline 8 & 152,33 & 94,86 & 62,35 \\
\hline 7 & 114,64 & 96,13 & 61,66 \\
\hline 6 & 144,04 & 71,07 & 71,12 \\
\hline 5 & 145,12 & 87,31 & 74,76 \\
\hline 4 & 121,79 & 64,12 & 57,55 \\
\hline 3 & 124,70 & 97,47 & 68,88 \\
\hline 2 & 151,42 & 90,09 & 71,28 \\
\hline 1 & 84,34 & 74,85 & 64,80 \\
\hline $\bar{x}$ & 134,72 & 85,34 & 69,63 \\
\hline $1^{2}$ & 425,01 & 131,86 & 47,70 \\
\hline
\end{tabular}

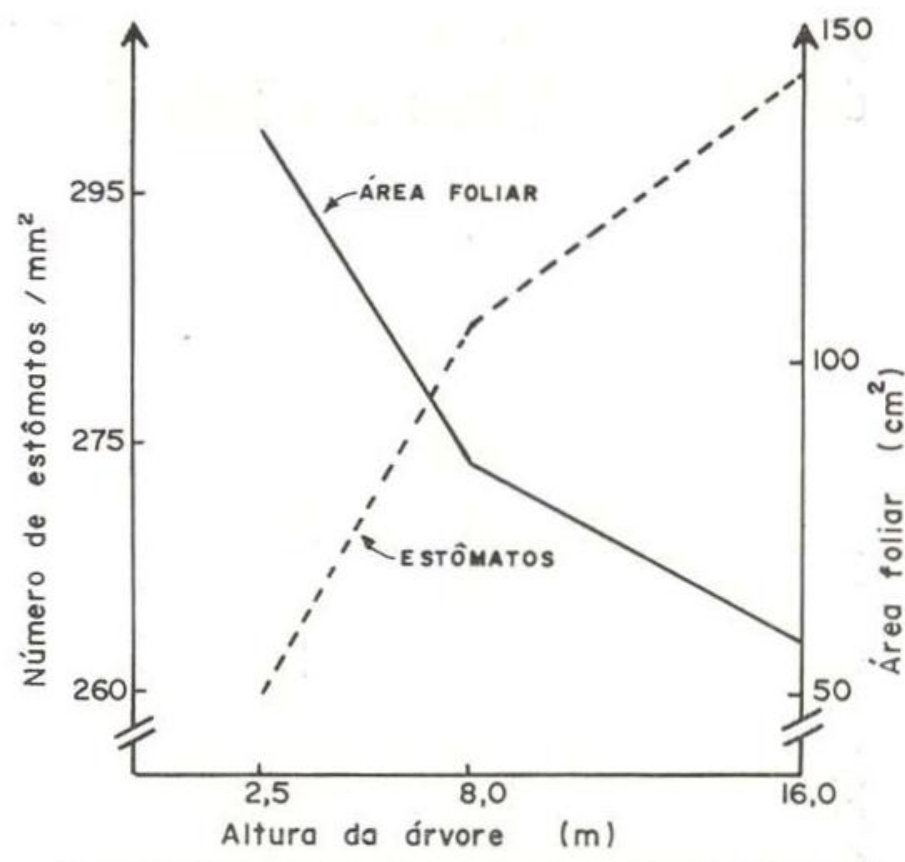

FIG. 1 - Relação entre o número de estômatos $/ \mathrm{mm}^{2}$ e área foliar de P. myrtifolia a diferentes alturas da copa da árvore.

tenham estômatos mais numerosos por unidade de área do que as folhas de inserção mais baixa. A média de estômatos $/ \mathrm{mm}^{2}$ (Tab. 2) e Fig. 1), evidencia um aumento do número de estômatos do estrato inferior para o superior da árvore com significância da ordem de $P<0,00001$ ao se comparar os três estratos, dois a dois. Os resultados obtidos por Medri \& Lleras (1979), como também por Leite \& Lleras (1978), apresentaram um aumento progressivo do número de estômatos do estrato inferior para o superior, embora nem sempre significativo quando comparados entre si.

ÁREA DAS CÉLULAS EPIDÉRMICAS - Como se observa na Tabela 3 as áreas das células epidérmicas se apresentam sensivelmente maiores no trato inferior em relação aos estratos mediano e superior da árvore. Do mesmo modo que para os estômatos, a significância entre os valores das áreas das células epidércas dos estratos quando comparados entre si. foi da ordem de $P<0,00001$. As células epidérmicas se apresentaram de forma regular, com paredes muito pouco sinuosas, em todos os estratos da árvore (Fig. 2), ao contrário do que foi observado por Leite \& Lleras (1978) e Medri \& Lleras $(1979,1980)$. 

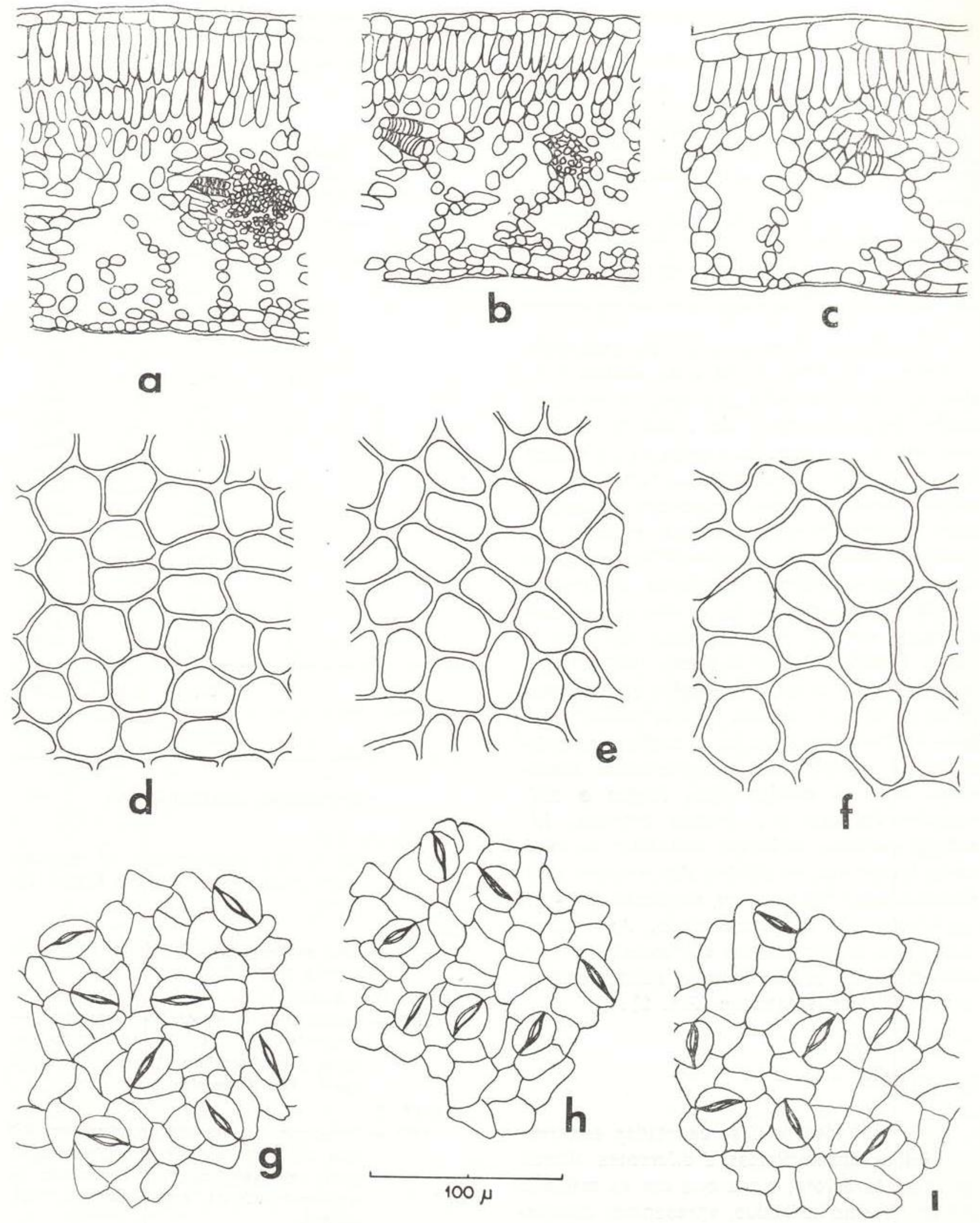

Fig. 2 - Aspectos anatômicos da folha de P. myrtifolia a-c, corte transversal do mesófilo; d-f, epiderme superior; g-i, epiderme inferior; a, d e g correspondem ao estrado superior; b, c e h correspondem ao estrato mediano; c, $f$ e i correspondem ao estrato inferior. 
TABELA 2 - Média do número de estômatos $/ \mathrm{mm}^{2}$ em Prunus myrtifolia.

\begin{tabular}{|c|c|c|c|}
\hline \multirow{2}{*}{ Folha } & \multicolumn{3}{|c|}{ Estratos da árvore } \\
\hline & Inferior & Mediano & Superior \\
\hline Ápice & 283,02 & 284,25 & 297,01 \\
\hline Meio & 267,12 & 287,79 & 282,70 \\
\hline Base & 230,55 & 237,10 & 270,69 \\
\hline $\bar{x}$ & 260,52 & 282,70 & 297,01 \\
\hline
\end{tabular}

MESÓFILO - Boardman (1977) estudando a estrutura de folhas de sol e de sombra, concluiu que alta luminosidade determina um acentuado desenvó́vimento do mesófilo, o que ocasiona um aumento na espessura da lâmina foliar. Em Prunus myrtifolia, as folhas do estrato superior da árvore apresentam o mesófilo mais espesso do que nos demais estratos, enquanto as espessuras dos mesófilos das folhas dos estratos mediano e inferior da árvore. quando comparados entre si, não apresentam diferença notória. Nos trabalhos de Leite \& Llerss (1978) \& Medri \& Lleras $(1979,1980)$ foi encontrado aumento gradativo na espessura do mesófilo do estrato inferior para o superior. No presente trabalho, o parênquima paliçádico no estrato superior apresenta-se bisseriado, com as células mais longas e mais compactadas que nos demais estratos. No estrato mediano, embora o paliçádico se apresente bisseriado, as células são menores e se dispõem mais frouxamente, enquanto no estrato inferior ele é monosseriado. As lacunas existentes no parênquima são maiores e bem delimitadas no estrato inferior, quando compa. radas aos demais estratos (Fig. 2).

\section{CONCLUSÕES}

Os resultados aqui apresentados sugerem que folhas desenvolvidas a diferentes alturas da copa da árvore, ainda que em se tratando de um mesmo indivíduo, apresentam características diferentes quanto a área foliar, número de estômatos por $\mathrm{mm}^{2}$ de área, área das células epidérmicas e estruturação do mesófilo. Isto leva à suposiçảo de que as folhas sofrem influência das condições microclimáticas existentes nos diferentes estratos da copa da árvore, confirmando estudos anteriores sobre o assunto.

TABELA 3 - Áreas das cólulas epidérmicas $\left(\mu \mathrm{m}^{2}\right)$ das folhas de Prunus myrtifolia a três diferentes estratos da árvore.

\begin{tabular}{c|rrr}
\hline & \multicolumn{4}{|c}{ Estratos da árvore } \\
\cline { 2 - 4 } \cline { 2 - 3 } Amostras & Inferior & Mediano & Superior \\
\cline { 2 - 4 } 1 & 72,0 & 70,0 & 43,0 \\
2 & 81,0 & 54,0 & 54,0 \\
3 & 104,0 & 63,0 & 52,0 \\
4 & 101,0 & 70,0 & 36,0 \\
5 & 52,0 & 64,0 & 73,0 \\
6 & 74,0 & 59,0 & 55,0 \\
7 & 107,00 & 48,0 & 47,0 \\
8 & 73,0 & 49,0 & 47,0 \\
9 & 118,0 & 71,0 & 43,0 \\
10 & 95,0 & 46,0 & 52,0 \\
11 & 84,0 & 55,0 & 36,0 \\
12 & 80,0 & 75,0 & 53,0 \\
13 & 74,0 & 49,0 & 54,0 \\
14 & 68,0 & 66,0 & 42,0 \\
15 & 68,0 & 49,0 & 73,0 \\
\hline $\bar{x}$ & 83,4 & 59,2 & 50,0 \\
\hline 12 & 322,54 & 97,31 & 122,35 \\
\hline
\end{tabular}

REFERENCIAS BIBLIOGRÁFICAS

BOARDMAN, N.K.

1977 - Comparative photosynthesis of sun and shade plants. Ann. Rev. Plant Physiol. 28: 355-77.

ESAU, K.

1965 - Plant anatomy. Second Edition. John Wiley \& Sons, Inc. 767p.

LEITE, A.M.C. \& LLERAS, E.

1978 - Ecofisiologia de plantas da Amazônia. 1 Anatomia foliar e ecofisiologia de Pogonophora schomburgkiana Miers, (Euphorbiaceae). Acta Amazonica, 8 (3): 365-370.

LLERAS, E.

1977 - Differences in stomatal number per unit area within the same species under differents micro-enviromental conditions: $A$ working hypothesis. Acta Amazonica, 7 (4): 473-476.

s/d - Aspectos Básicos da Morfologia das folhas e sua relação com parâmetros fisiológicos. Anais do II Congresso Latino-Americano de Botânica. 
MEDINA, E.

1972 - Ecofisiologia vegetal: aspectos teóricos y aplicados. Bol. Soc. Ven. Cien. Nat., 30: 124-125.

MEDRI, M.E. \& LLERAS, E.

1979 - Ecofisiologia de plantas da Amazônia. 2 Anatomia foliar e ecofisiologia de Bertholletia excelsa Humb. \& Bonpl. (Castanha-dopará) - Lecythidaceae. Acta Amazonica, 10 (2).

1980 - Aspectos da Anatomia Ecológica de Folhas de Hevea brasiliensis Müell. Arg. Acta Amazonica, 10 (3): 463-493.
MEIDNER, H. \& MANSFIELD, T.A.

1968 - Physiology of stomata. Mc-Graw-Hill. London. $179 p$.

SALISBURY, E.J.

1927 - On the causes and ecological significance of stomatal frequency, with special reference to woodland and flora. Phil. Trans. Roy. Soc. London. Ser. B, 46: 1-65.

SIEGEL, S.

1956 - Nonparametric statistics for the behavioral Sciences. Mc-Graw-Hill. New York. 312p.

(Aceito para publicação em $05 / 02 / 82$ ) 